Anggun Wulandari, Rina Dian Rahmawati. (2019). Tingkat Ploidi Paku Sayur (Diplazium esculentum) pada Ketinggian yang Berbeda di Gunung Merbabu, Boyolali, Jawa Tengah, Indonesia. Vol. 5 (1) Pp. 11-15. Doi: 10.23917/ bioeksperimen.v5i1.2795

\title{
TINGKAT PLOIDI PAKU SAYUR (Diplazium esculentum) PADA KETINGGIAN YANG BERBEDA DI GUNUNG MERBABU, BOYOLALI, JAWA TENGAH, INDONESIA
}

\author{
Anggun Wulandari*; Rina Dian Rahmawati \\ Universitas KH. A. Wahab Hasbullah \\ Jl. Garuda No. 09 Tambakberas, Jombang, 61451 \\ "Email: anggun.4w@gmail.com
}

\begin{abstract}
Abstrak
Pada tumbuhan paku sering terjadi fenomena poliploidi dan salah satu penyebab yang diduga dapat menimbulkan peristiwa poliploidi adalah suhu dingin. Oleh karena itu penelitian ini bertujuan untuk mengetahui tingkat ploidi paku sayur (Diplazium esculentum) pada ketinggian yang berbeda di Gunung Merbabu. Penelitian ini merupakan penelitian eksperimen menggunakan Rancangan Acak Lengkap (RAL). Objek yang digunakan adalah tumbuhan paku Diplazium esculentum yang diambil dari ketinggian yang berbeda ( $\pm 500 \mathrm{mdpl}, \pm 1500 \mathrm{mdpl}$, dan $\pm 2500 \mathrm{mdpl})$ di salah satu gunung tinggi Indonesia, yaitu Gunung Merbabu. Hasil penelitian menunjukkan bahwa terdapat perbedaan tingkat ploidi Diplazium esculentum pada ketinggian yang berbeda. Tumbuhan paku Diplazium esculentum yang berada pada ketinggian $\pm 500 \mathrm{mdpl}$ menunjukkan hasil tipe sitologi diploid (2n) yang memiliki jumlah rata-rata kromosom adalah 54,2; pada ketinggian $\pm 1500 \mathrm{mdpl}$ menunjukkan hasil tipe sitologi triploid (3n) yang memiliki jumlah rata-rata kromosom adalah 80,533; sedangkan pada ketinggian $\pm 2500 \mathrm{~m}$ dpl memiliki jumlah rata-rata kromosom sebanyak 105,333 dengan hasil tipe sitologi tetraploid (4n). Dapat disimpulkan bahwa terdapat perbedaan tingkat ploidi Diplazium esculentum pada masing-masing ketinggian di Gunung Merbabu.
\end{abstract}

Kata kunci: Diplazium esculentum, gunung merbabu, kromosom, poliploidi.

\begin{abstract}
Fern plant is common polyploidy phenomenon and one of the causes that is suspected to cause polyploidy events is cold temperatures. Therefore, this research aims to determine the level of ploidi fern vegetables (Diplazium esculentum) at different altitude in Merbabu Mountain. This research is an experimental research using Completely Randomized Design (CRD). The object used is the Diplazium esculentum/ fern plant taken from different altitude ( \pm 500 masl, \pm 1500 masl, and \pm 2500 masl) in one of Indonesia's high mountains, namely Merbabu Mountain. The research results showed that there were differences in ploidy levels of Diplazium esculentum at different altitude. Diplazium esculentum located at an heights of \pm 500 masl showed the result of diploid cytological type (2n) which has an average number of chromosomes was 54.2; at an heights of \pm 1500 masl indicated the result of triploid cytological type (3n) which has an average number of chromosomes was 80.533; while at an heights of \pm 2500 masl has an average number of chromosomes as much as 105.333 with tetraploid cytological type results (4n). Thus it can be concluded that there is a difference in ploidy level of Diplazium esculentum at each altitude in Merbabu Mountain.
\end{abstract}

Keywords: Diplazium esculentum, merbabu mountains, chromosomes, polyploidy

\section{Pendahuluan}

Tumbuhan paku (Pterydophyte) merupakan tumbuhan berpembuluh (Yatskievych, 2002), peralihan antara tumbuhan rendah ke tinggi (tumbuhan kormofita). Tumbuhan paku merupakan tumbuhan kosmopolit dengan distribusi sangat luas mulai daerah tropis hingga dekat kutub utara dan selatan, hutan primer, hutan sekunder, alam terbuka, dataran rendah hingga dataran tinggi, lingkungan yang lembab, basah, rindang, kebun tanaman, bahkan di pinggir jalan. Indonesia merupakan salah satu Negara tropis dimana tumbuhan paku tersebar di seluruh bagian (Sandy, Pantiwati, Huda, \& Latifah, 2016).

Tumbuhan paku masih jarang diperhatikan padahal memiliki banyak fungsi serta sebagai sumber keragaman hayati yang perlu dijaga dan 
dilestarikan. Tumbuhan paku sebenarnya memiliki fungsi ekologis yaitu sebagai penutup tanah sehingga berfungsi mengatur tata air dan mencegah terjadinya erosi serta menjaga ekosistem hutan (Sharpe, Mehltreter, \& Walker, 2010).

Paku sayur (Diplazium esculentum) merupakan sejenis paku/ pakis yang banyak dikonsumsi masyarakat karena memiliki rasa yang cukup enak. Masyarakat lebih menyukai ental muda yang ukurannya besar, bahkan orang terdahulu memanfaatkan tumbuhan ini untuk menyembuhkan berbagai macam penyakit. Kajian tentang tumbuhan paku menyatakan bahwa tumbuhan yang bersifat poliploid umumnya memiliki ukuran morfologi yang lebih besar dibandingkan tanaman diploid (Turot, Polii, \& Walangitan, 2016).

Poliploidi merupakan keadaan bahwa individu memiliki lebih dari duagenom dan merupakan gejala yang umum dan tersebar luas dalam tumbuhan (Wang, Chen, \& Xiang, 2007). Fenomena poliploidi ini sering terjadi pada tumbuhan paku yang merupakan akibat dari berbagai proses baik secara meiotik ataupun secara somatic (Segraves \& Anneberg, 2016). Berbagai spesies paku dan tumbuhan terdapat sebagai sitotipe poliploid (Chen, Sun, \& Sun, 2009). Salah satu penyebab yang diduga dapat menimbulkan peristiwa poliploidi adalah suhu dingin, berkaitan dengan hal tersebut, terdapat pendapat yang menyatakan bahwa pada daerah dengan ketinggian yang lebih tinggi dan suhu yang lebih rendah, cenderung ditemukan tumbuhan paku dengan tingkat ploidi yang lebih besar (Hori, et al., 2018).

Data yang memuat tentang variasi jumlah kromosom (tingkat ploidi) pada tiap-tiap ketinggian gunung belum banyak ditemukan padahal paku sayur merupakan salah satu potensi hasil hutan non kayu yang cukup besar dan sampai saat ini belum tersentuh oleh teknologi seperti dalam bentuk pengolahan atau pengemasannya (Wulandari \& Rahmawati, 2018). Berdasarkan hal tersebut maka perlu dilakukan penelitian lebih lanjut mengenai "Tingkat Ploidi Paku Sayur (Diplazium esculentum) pada Ketinggian yang Berbeda di Gunung Merbabu”.

Gunung Merbabu adalah salah satu gunung inaktifdi Indonesia. GunungMerbabu (3.142 mdpl) secara geografis terletak pada koordinat $110^{\circ} 26^{\prime} 22^{\prime \prime}$
BT dan $7^{\circ} 27^{\prime} 13^{\prime \prime}$ LS, secara administratif dikelilingi oleh tiga Kabupaten yaitu Magelang, Semarang, dan Boyolali, Provinsi Jawa Tengah. Gunung Merbabu memiliki keanekaragaman hayati yang cukup tinggi dan masih banyak ditemukan tumbuhan paku diantaranya adalah paku sayur. Terdapat berbagai jenis vegetasi yang bisa ditemui di kawasan tersebut. Tanah yang subur dan suhu udara yang sejuk membuat daerah ini banyak ditumbuhi tanaman termasuk paku sayur. Paku ini tumbuh di tebingtebing yang lembap dan teduh (Prastyo, Heddy, \& Nugroho, 2015).

\section{Material dan Metode}

Penelitian dilaksanakan bulan Juni - Juli 2018. Tempat penelitian mulai dari pengambilan sampel Diplazium esculentum dilakukan di Gunung Merbabu pada ketinggian yang berbeda yaitu $\pm 500 \mathrm{mdpl}, \pm 1500 \mathrm{mdpl}$ dan $\pm \mathrm{v} 2500 \mathrm{mdpl} \mathrm{dan}$ Penghitungan jumlah kromosom untuk mengetahui tingkat ploidi dilakukan di Laboratorium Universitas KH. A. Wahab Hasbullah, Jombang, Jawa Timur, Indonesia.

Penelitian ini merupakan penelitian eksperimen dengan menggunakan rancangan acak lengkap (RAL) yang memaparkan tentang tingkat ploidi paku sayur (Diplazium esculentum) pada ketinggian yang berbeda di Gunung Merbabu.

Alat yang digunakan dalam penelitian ini adalah mikroskop binokuler, waterbath, ruang asam, altimeter dan kamera digital untuk dokumentasi hasil pengamatan. Bahan yang digunakan adalah $\mathrm{HCl} 1 \mathrm{~N}$, alkohol $95 \%$, asam asetat glacial $100 \%$, formalin $4 \%$, akuades, acetocarmin, tudung akar Diplazium esculentum.

\section{Prosedur Penelitian}

\section{a. Pembuatan Larutan FAA (Formalin Aseto-Alkohol)}

Menyiapkan akuades sebanyak $20 \mathrm{ml}$ dalam botol, kemudian menuangkan $70 \mathrm{ml}$ alkohol 95\% secara perlahan, menuangkan $5 \mathrm{ml}$ formalin $4 \%$ secara perlahan, menuangkan $5 \mathrm{ml}$ asam asetat glacial $100 \%$ secara perlahan, kemudian menutup botolnya dan digoyangkan secara perlahan. Pembuatan larutan FAA ini dilakukan di 
dalam ruang asam dengan menggunakan sarung tangan dan masker.

\section{b. Persiapan Sampel}

Mengambil tumbuhan paku Diplazium esculentum di Gunung Merbabu pada ketinggian $\pm 500 \mathrm{mdpl}, \pm 1500$ mdpl dan \pm 2500 mdpl kemudian memasukkannya kedalam kantong plastik dengan tetap menjaga kelembaban agar tumbuhan paku tidak mati, kemudian menanam tumbuhan yang telah diambil dari lokasi dalam polibag untuk menstimulasi perkembangan akar-akar yang baru.

\section{c. Pembuatan Preparat}

Memotong ujung akar $\pm 1 \mathrm{~cm}$ dari tudung akar yang berwarna putih kemudian dimasukkan ke dalam botol vial yang berisi larutan FAA, pemotongan dilakukan pada pukul 09.30 WIB, kemudian mengeluarkan potongan akar dari larutan FAA dan mencuci tudung akar tersebut dengan air kran sebanyak 8 kali, setelah itu memasukkan potongan akar yang telah dicuci ke dalam botol vial yang berisi $\mathrm{HCl} 1 \mathrm{~N}$ dan memasukkannya ke dalam waterbath dengan suhu $60^{\circ}$. Menyalakan waterbath sampai dua lampunya menyala, dan setelah 15 menit waterbath dimatikan, kemudian botol vial dikeluarkan dan di diamkan selama 8 menit. Selanjutnya meletakkan potongan akar pada kaca benda dan memotong bagian tudung akar kemudian menetesi potongan akar tersebut dengan acetocarmin dan didiamkan selama beberapa menit sampai potongan akar terlihat merah. Menutup kaca benda dengan kaca penutup kemudian ditekan dengan ibu jari, selanjutnya mengamati preparat dibawah mikroskop binokuler dengan perbesaran 1000 kali.

\section{Teknik Pengumpulan Data}

Teknik pengumpulan data dalam penelitian ini dilakukan penghitungan jumlah kromosom dengan mencari 5 sel tudung akar dan setiap sel dihitung sebanyak 3 kali ulangan yang mengalami pembelahan mitosis pada tahap metafase atau anafase. Kemudian menghitung jumlah kromosom pada masing-masing sel dengan menggunakan hand counter, selanjutnya menentukan tipe ploidinya.

\section{Analisis Data}

Data yang diperoleh langsung dianalisis dengan analisis one way Anova dengan SPSS. Jika hasil analisis $\mathrm{F}$ hitung $>\mathrm{F}$ tabel ${ }_{0,05}$, maka dilakukan uji lanjut dengan Post Hoc Analysis Least Significant Difference (LSD) dengan taraf signifikansi 5\% untuk mengetahui tingkat ploidi paku sayur (Diplazium esculentum) pada ketinggian yang berbeda di Gunung Merbabu.

\section{Hasil dan Pembahasan}

\section{Hasil}

Hasil penelitian tingkat ploidi paku sayur (Diplazium esculentum) pada ketinggian yang berbeda di Gunung Merbabu dilihat dari rerata jumlah kromosom pada sel yang ditemukan pada masing-masing ketinggian yaitu $\pm 500 \mathrm{mdpl}, \pm 1500$ mdpl dan \pm 2500 mdpl. Data jumlah kromosom Diplazium esculentum pada masing-masing ketinggian dapat dilihat pada Tabel 1 .

Berdasarkan data pada Tabel 1 dapat diketahui bahwa jumlah kromosom yang diamati pada sel tudung akar Diplazium esculentum pada ketinggian \pm 500 mdpl memiliki rata-rata jumlah kromosom sebanyak 54,2; pada ketinggian $\pm 1500 \mathrm{mdpl}$ memiliki rata-rata jumlah kromosom sebanyak 80,533; sedangkan pada ketinggian $\pm 2500 \mathrm{mdpl}$ memiliki rata-rata jumlah kromosom yang paling banyak yaitu 105,333.

Tumbuhan paku memiliki jumlah kromosom dasar sebanyak 29, sehingga tumbuhan paku yang dinyatakan sebagai individu diploid memiliki jumlah kromosom somatik 58, sedangkan individu triploid memiliki jumlah kromosom 87 dan tetraploid 116. Dari hasil analisis data dapat diketahui bahwa tingkat ploidi pada tumbuhan paku Diplazium esculentum yang berada pada ketinggian \pm 500 mdpl memiliki rerata set kromosom sebesar 1,869 sehingga menunjukkan hasil tipe sitologi diploid (2n), pada ketinggian \pm 1500 mdpl memiliki rerata set kromosom sebesar 2,777 sehingga menunjukkan hasil tipe sitologi 
triploid (3n), sedangkan pada ketinggian \pm 2500 mdpl memiliki rerata set kromosom sebesar 3,632 sehingga menunjukkan hasil tipe sitologi tetraploid (4n) (Praptoswiryo, 2008).

Poliploid dapat terjadi secara spontan maupun sebagai akibat perlakuan, poliploidi secara alami dapat terjadi karena faktor:

a. Penggandaan somatik. Sel somatik mengalami penggandaan secara tidak beraturan, pada saat pembelahan mitosis dihasilkan sel-sel meristematik yang mengganda tanpa mengalami pembelahan yang menyebabkan kelipatan jumlah kromosom pada generasi berikutnya dalam individu tersebut.

Tabel 1. Rerata Jumlah Kromosom Diplazium esculentum di Gunung Merbabu

\begin{tabular}{cccc}
\hline Ketinggian & Rerata & $\begin{array}{c}\text { Rata- } \\
\text { rata/29 }\end{array}$ & Tipe ploidi \\
\hline $\pm 500 \mathrm{mdpl}$ & 54,2 & 1,869 & Diploid \\
$\pm 1500 \mathrm{mdpl}$ & 80,533 & 2,777 & Triploid \\
$\pm 2500 \mathrm{mdpl}$ & 105,333 & 3,632 & Tetraploid \\
\hline
\end{tabular}

b. Sel reproduksi mengalami reduksi secara tidak beraturan yaitu perangkat kromosom gagal berpisah menuju kutub ekuator pada saat anafase sehingga perangkat kromosom tidak memisah dan tetap pada bidang ekuator dalam inti. Hal ini menyebabkan sel memiliki jumlah kromosom ganda (dua kali jumlah kromosom normal)

\section{Pembahasan}

Berdasarkan data yang telah diperoleh menunjukkan bahwa semakin tinggi tempat didapatkannya tumbuhan paku Diplazium esculentum menunjukkan jumlah kromosom juga semakin banyak. Diplazium esculentum mengalami poliploidi karena proses penggandaan kromosom sehingga jumlah kromosom somatiknya berlipat dari jumlah kromosom dasarnya. Tingkat ploidi ini dipengaruhi oleh faktor ketinggian tempat. Sebagaimana diketahui bahwa semakin tinggi suatu tempat maka semakin rendah suhunya. Faktor ketinggian tempat berpengaruh pada tumbuhan paku karena adanya kecenderungan sitologi pada tumbuhan paku. Suhu dan kelembapan yang mempengaruhi tumbuhan paku pada perkembangan siklus hidup sejak germinasi spora sampai maturasi sporofit.

Faktor lingkungan secara langsung maupun tak langsung dapat mempengaruhi reorganisasi kromosom. Dalam penelitian ini, semakin tinggi ketinggian tempat menunjukkan tingkat ploidi yang semakin besar di Gunung Merbabu, hal ini diduga karena semakin menurunnya temperatur. Temperatur dan faktor lain yang terkait dengan ketinggian tempat berperan dalam ploidisasi tumbuhan. Tingginya derajat ploidi dan peristiwa poliploidi juga dipengaruhi oleh kondisi iklim dan sejarah bencana alam.

Pengujian dengan menggunakan one way Anova yang sudah dilakukan peneliti menunjukkan terdapat perbedaan jumlah kromosom Diplazium esculentum pada ketinggian $\pm 500 \mathrm{mdpl}, \pm 1500$ mdpl, dan \pm 2500 mdpl. Hasil uji lanjut dengan Post Hoc Analysis Least Significant Difference (LSD) dapat diketahui bahwa jumlah kromosom Diplazium esculentum pada ketinggian \pm 500 mdpl berbeda signifikan dengan ketinggian $+1500 \mathrm{mdpl}$ dan $\pm 2500 \mathrm{mdpl}$, hal ini ditunjukkan dengan nilai $\mathrm{F}$ hitung $(143,27)>$ F tabel $_{0,05}(3,885)$.

Dari penelitian ini dapat disimpulkan bahwa Diplazium esculentum yang ditemukan di Gunung Merbabu ditemukan tumbuhan poliploid di atas ketinggian \pm 1500 mdpl. Jika dilihat dari distribusinya menunjukkan bahwa tumbuhan poliploid mempunyai distribusi yang lebih luas dari pada yang diploid. Tumbuhan diploid ditemukan di ketinggian \pm 500 mdpl, sedangkan tumbuhan poliploid ditemukan pada ketinggian $\pm 1500 \mathrm{mdpl}$ dan $\pm 2500 \mathrm{mdpl}$

\section{Simpulan}

Diplazium esculentum memiliki tingkat ploidi yang berbeda pada setiap ketinggian, dimana jumlah kromosom tumbuhan paku Diplazium esculentum pada ketinggian $\pm 500 \mathrm{mdpl}$ memiliki rerata jumlah kromosom 54,2 dengan hasil tipe sitologi diploid (2n); pada ketinggian \pm 1500 mdpl memiliki rerata jumlah kromosom 80,533 dengan hasil tipe sitologi triploid (3n); sedangkan pada ketinggian \pm 2500 mdpl memiliki jumlah rata-rata 
kromosom sebanyak 105,333 dengan hasil tipe tingkat ploidi Diplazium esculentum pada masingsitologi tetraploid (4n). Jadi, terdapat perbedaan masing ketinggian di Gunung Merbabu.

\section{Daftar Pustaka}

Chen, G., Sun, W. B., \& Sun, H. (2009). Morphological characteristics of leaf epidermis and size variation of leaf flower and fruit in different ploidy levels in Buddleja macrostachya (Buddlejaceae). Journal of Systematics and Evolution, Vol 47 (3): 231-236 .

Hori, K., Zhou, X., Shao, W., Yan, Y. H., Wang, R. X., \& Murakami, N. (2018). New Diploid Sexual Cytotypes of Dryopteris sect. Erythrovariae (Dryopteridaceae) in China. Acta Phytotax. Geobot., Vol 69 (2): 127-133.

Praptoswiryo, T. N. (2008). Biosystematic Study of The Fern Genus Diplazium in West Malesia. Bogor, Indonesia : IPB Press.

Prastyo, W. R., Heddy, S., \& Nugroho, A. (2015). Identifikasi Tumbuhan Paku Epifit pada Batang Tanaman Kelapa Sawit (Elaeis guineensis J.) di Lingkungan Universitas Brawijaya . Jurnal Produksi Tanaman, Volume 3, Nomor 1: 65-74.

Sandy, S. F., Pantiwati, Y., Huda, A. M., \& Latifah, R. (2016). Keanekaragaman Jenis Tumbuhan Paku (Pterydophyta) di Kawasan Air Terjun Lawean Sendang Kabupaten Tulungagung . Seminar Nasional II UM Malang (pp. 828-836). Malang, Jawa Timur, Indonesia : UM Malang Press.

Segraves, K. A., \& Anneberg, T. J. (2016). Species interactions and plant polyploidy . American Journal of Botany, Vol 103 (10) : $1-10$.

Sharpe, J. M., Mehltreter, K., \& Walker, L. R. (2010). Ecological importance of ferns. In L. R. Klaus Mehltreter, \& J. M. Sharpe., Fern Ecology (pp. 1-21). Sussex, England: Cambridge University Press .

Turot, M., Polii, B., \& Walangitan, H. D. (2016). Potensi Pemanfaatan Tumbuhan Paku Diplazium esculentum Swartz (Studi kasus) di Kampung Ayawasi Distrik Aifat Utara, Kabupaten Maybrat, Provinsi Papua Barat. Agri-SosioEkonomi Unsrat, Volume 12 Nomor 3A : 1 - 10.

Wang, Y., Chen, X., \& Xiang, C.-B. (2007). Stomatal Density and Bio-water Saving. Journal of Integrative Plant Biology, Vol 49 (10): 1435-1444.

Wulandari, A., \& Rahmawati, R. D. (2018). Tingkat Ploidi Paku Sayur (Diplazium esculentum) pada Ketinggian yang Berbeda di Gunung Semeru. Edubiotik, Vol. 3, No. 2 : Hal 58-63.

Yatskievych, G. (2002). Pteridophytes (Ferns). St Louis, MO, USA: John Wiley \& Sons. 